\title{
26. Die Altertumswissenschaften nach 1945:
}

Hermann Bengtson

A m 6. Juni 1944 landeten die Alliierten in der Normandie. Die zweite Front war eröffnet und das Ende des «Dritten Reiches» abzusehen. Am selben Tag schrieb der Professor der Alten Ge-
Bengtson désire passer son temps à une compilation plutôt qu'à des travaux origenaux. Louis Robert an Günther Klaffenbach, 15. Juni $1953^{1}$ schichte an der Universität Jena, Hermann Bengtson, ${ }^{2}$ an Georg Sund und bedankte sich für die Zusendung von fünf Freiexemplaren des zweiten Bandes seiner monumentalen Qualifikationsschrift über die «Strategie in der hellenistischen Zeit», die gerade in den bei C.H.Beck verlegten «Münchener Beiträgen zur Papyrusforschung und antiken Rechtsgeschichte» erschienen war. Er dankte dem Verlag «aufrichtig für die hervorragende Ausführung des Buches, an dem ich viel Freude habe», und fügte hinzu: «Die Ausstattung ist ja wahrhaft noch ganz friedensmäßig!» ${ }^{3}$ Hermann Bengtson verstand sich auf Krieg und Frieden. 1909 geboren, war er Angehöriger der Kriegsjugendgeneration, die durch Krieg, Niederlage und Nachkriegsnot geprägt wurde. ${ }^{4}$ Er war national gesinnt, fürchtete linke Parteien und zeigte Sympathien für die völkische Bewegung. Nach seiner Promotion in München bei Walter Otto und seiner Habilitation 1940 in Heidelberg bei Fritz Schachermeyr war ihm 1942 die althistorische Professur in Jena übertragen worden.

1936 hatte er den Verlag C.H.Beck zum ersten Mal betreten, um die Drucklegung seines Buches zu besprechen. Seine akademische Karriere wurde zweimal durch den Militärdienst unterbrochen. Bereits am zo. September 1939 war er zur Wehrmacht eingezogen worden und kämpfte bis 1941 an der Ostfront, von wo der Leutnant der Reserve Briefe an den Rektor der Universität München, den nationalsozialistischen Multifunktionär Walther Wüst, schrieb, in denen er die Botschaft von der Überlegenheit des deutschen Soldaten über den russischen Untermenschen verkündete. ${ }^{5}$ Seit dem 15. Mai 1944 trug der Extraordinarius wieder den grauen Rock und wartete in einer Garnison in Kassel auf seinen Einsatz. In dem Brief an Georg Sund regelte er so nicht nur den Druckkostenzuschuss, sondern zeigte sich von dem Geschehen im Westen beeindruckt: «Heute 
morgen ist die Invasion im Westen erfolgt. Wie klein erscheint gegenüber diesem ungeheuren Geschehen doch das kleine Einzelschicksal!»

Wenig später wurde der habilitierte Historiker als Kriegstagebuchführer der nach Stalingrad neu aufgestellten 6. Armee nach Bessarabien abkommandiert. Von dort korrespondierte er mit der Heimat. Nachdem Bengtson von der Witwe seines 194,1 verstorbenen Lehrers Walter Otto erfahren hatte, dass das Verlagshaus bei den letzten Angriffen auf München Schaden erlitten habe, bat er am 5.August 1944 Sund, «auch Herrn Dr. Beck» seine aufrichtige Anteilnahme «am Schicksal des Verlages» mitzuteilen, mit dem er sich seit Jahren verbunden fühle. Er lebe im Osten «wie in den Kolonien», die Heimat sei in unerreichbare Ferne gerückt. «Da das Leben hier in verhältnismäßiger Ruhe dahinfließt, so machen die Nachrichten über den feindlichen Luftterror im Reich einen um so tieferen Eindruck. Möge die Zeit der Prüfungen bald vorüber sein!» Dann berichtete er von seinen Eindrücken und blickte nicht mehr ganz so siegesgewiss in die Zukunft: «Die Gegend, bis 1940 von Volksdeutschen bewohnt, war früher einmal ein Land, in dem Milch und Honig floss. Heute fließt dies alles nur noch tropfenweise, und wir selbst, im Lande unseres Verbündeten lebend, haben kein Geld, um die Produkte des Landes zu bezahlen. Trotzdem ist aber der Unterschied zwischen Russland und unserer Gegend sehr groß; man merkt, dass man auf dem Boden einer uralten Zivilisation steht, die sich - hoffentlich - gegen den Ansturm des Ostens behaupten wird. An uns soll es nicht fehlen.» Er fuhr fort: «Es erscheint angesichts des ungeheuren Geschehens in unseren Tagen kaum zu rechtfertigen, wenn man von seinem eigenen Schicksal, das völlig unwesentlich ist, berichtet.» Er sei Ende Juni angekommen und habe eine Tätigkeit übernommen, die gar nicht übermäßig anstrengend, aber doch einigermaßen anregend genannt werden könne. «Wir leben hier zur Zeit - wie lange noch? - in einer sehr ruhigen Ecke, während die ganze Ostfront mehr oder weniger in Bewegung ist. Aber das kann sich eines Tages ändern, denn die Konstellationen wechseln blitzschnell, wenn man etwa an den Abbruch der Beziehungen zwischen der Türkei und uns denkt.» ${ }^{6}$

Am 24. August dankte Sund für den Brief und «die ausführliche Schilderung» der militärischen Situation. Er zeigte sich informiert: «Inzwischen ist es auch im Süden der Ostfront wieder sehr lebhaft geworden. Offenbar ist auch dort der Ansturm der Russen sehr groß.» Man werde also in dem Kriegstagebuch, dessen Führung Bengtson, früheren Ankündigungen entsprechend, übernommen habe, «nicht nur Erfreuliches zu notieren haben. Hoffentlich ist das Facit dann doch gut.» Sund berichtete im Weiteren über 
die Schäden des Bombenangriffs, wies darauf hin, dass die Produktionsstätten noch intakt seien und auch das Verlagsbüro weiter bestehe und die Arbeiten fortgeführt würden. Doch «das schöne Verlagshaus Wilhelmstraße 9 ist allerdings bis in den Keller ausgebrannt. Zunächst schien es, als könne man des Brandes Herr werden. Dann aber hat eine Sprengbombe den Luftschutzkeller eingedrückt und zwei Angestellte verschüttet. Als sie glücklich geborgen waren, hatte sich der Brand so ausgebreitet, dass nichts mehr zu machen war und auch nur wenig gerettet werden konnte. Dass der ideelle und materielle Verlust für den Verlag sehr groß ist, brauche ich Ihnen nicht zu sagen. Herr Dr. Beck lässt Ihnen für Ihre Teilnahme herzlich danken. Meine Privatwohnung ist trotz der Verwüstungen ringsum erhalten geblieben. Ich habe auch insofern Glück gehabt, als ich an jenem Mittwoch zufällig eine halbe Stunde früher zu Tisch gefahren war als sonst.» ${ }^{7}$

Mitten im Chaos des zusammenstürzenden «Dritten Reiches» und trotz der Zerstörungen des Bombenkriegs versuchten Verlagsmitarbeiter und Autor, die Fiktion der kontinuierlichen Buchproduktion aufrechtzuerhalten und dem Tagesgeschäft nachzugehen, d.h., die Drucklegung des dritten Bandes der «Strategie in der hellenistischen Zeit» voranzutreiben. Die militärische Realität war jedoch so überwältigend, dass das Kriegsgeschehen sowohl an der Front wie in der Heimat in die Kommunikation integriert werden musste und mehr und mehr Raum in der Korrespondenz einnahm. Sunds Brief von Ende August 1944 dürfte Bengtson nicht mehr erreicht haben. Denn die Hoffnung, die der Kriegstagebuchführer Anfang des Monats geäußert hatte, dass sich bis Oktober manches zugunsten der Wehrmacht klären könne, trog. Die 6. Armee ging im Sommer unter. 170000 Soldaten fielen. Unter den wenigen Überlebenden war Hermann Bengtson, der sich zusammen mit dem Oberkommando dem sowjetischen Großangriff durch Flucht entzogen hatte. Sein Kriegstagebuch gilt als verschollen.

In der Heimat geriet Bengtson in amerikanische Kriegsgefangenschaft. Nach seiner Entlassung kehrte er nicht mehr auf seine Professur in Jena zurück, das in der russischen Zone lag. Seine Bibliothek und sein Barvermögen verlor er. Großes Ungemach drohte auch im Entnazifizierungsverfahren. Im «Dritten Reich» hatte Bengtson wie andere Nachwuchswissenschaftler Bekenntnisgesten und Loyalitätsleistungen erbracht, um seine Karriere nicht zu gefährden. Als «Märzgefallener» war er 1933 Mitglied der NSDAP geworden, hatte sich seit 1937 als Sturmmann und dann als Rottenführer der SA betätigt, seit 1938 dem NS-Dozentenbund angehört 
und Beiträge für die Nationalsozialistische Volkswohlfahrt gezahlt. ${ }^{8}$ Ein überzeugter Nationalsozialist war er nicht gewesen, genauer: er war es nicht lange gewesen. Die anfängliche, aus antiparlamentarischen und antiliberalen Ressentiments gespeiste Begeisterung für die «nationale Erhebung» kühlte rasch ab; der junge Gelehrte stieß sich an der dümmlichen Rhetorik der Volksschullehrer mit Braunhemd und Ledergürtel, wie er später schrieb. ${ }^{9}$ Aber an Opposition dachte Bengtson nicht. An der Universität München leitete er eine Arbeitsgruppe über das «Eindringen des Judentums in die antike Welt» ${ }^{10}$, und von verschiedenen Untergliederungen der NSDAP wurde ihm bescheinigt, weder ein «Stubengelehrter» noch ein «weltfremder Bücherwurm» zu sein. ${ }^{11}$

\section{Zurück zur Alten Geschichte}

Im Spruchkammerverfahren stand Sund dem Althistoriker bei. Die Loyalität des Verlags zu seinen Autoren war von Bestand. Sund erklärte am 9. Mai 1946 eidesstattlich, er kenne Bengtson seit 1937 als «einen klar und nüchtern denkenden, allein der Erforschung der geschichtlichen Wahrheit dienenden Gelehrten». Sie hätten anlässlich der Drucklegung seiner wissenschaftlichen Arbeiten auch immer wieder politische Gespräche geführt, und dabei habe Bengtson «in seiner freimütigen Art von vornherein am Nationalsozialismus Kritik geübt». Zunächst habe er nur an der «Knebelung der Wissenschaft» Anstoß genommen, aber bald habe er sich kritisch über die Politik Hitlers und der NSDAP geäußert. Er, Sund, habe immer den Eindruck gehabt, dass Bengtson in seinem Kreis gegen die autoritären Lehrmeinungen des nationalsozialistischen Staates und «gegen die vernebelnde Wirkung der Propaganda aufgetreten» sei. ${ }^{12}$ Sunds «Persilschein» bewirkte nicht viel. Bengtson wurde als «Mitläufer» eingestuft. Das Urteil akzeptierte er ebenso wie die Geldbuße in Höhe von 500 Reichsmark. In München, wohin er übersiedelte, musste er neu beginnen. Zunächst durfte Bengtson seinen Beruf nicht ausüben. ${ }^{13}$ Seine Kontakte zum Verlag sicherten wirtschaftlich seine Existenz.

Bengtson war nicht der einzige Althistoriker, den der Verlag nach 1945 finanziell unterstützte. Heinrich Beck half ebenso seinem Vetter Helmut Berve, der das althistorische Ordinariat erst in Leipzig und seit 1943 an der Ludwig-Maximilians-Universität innegehabt hatte. Kaum war Berve nach München berufen worden, war er ein gern gesehener Gast im Hause Beck. ${ }^{14}$ Am 1. Dezember 1944 besprach der Verleger mit ihm bei einer pri- 
vaten Zusammenkunft die Zukunft des «Handbuchs der Altertumswissenschaft». ${ }^{15}$ Da sich Berve im «Dritten Reich» aus freien Stücken zum Nationalsozialismus bekannt hatte und die rassistische Geschichtsschreibung in der Alten Geschichte heimisch machen wollte, wurde er nach dem Ende des Tausendjährigen Reiches verhaftet und amtsenthoben. Heinrich Beck stand zu seinem Verwandten. Die eigenen Schwierigkeiten im Zuge der Entnazifizierung ließen die Solidarität wachsen. Darüber hinaus traf man sich unmittelbar nach dem Ende des Krieges alle drei bis vier Wochen zum «Historischen Kränzchen», das aus zehn Teilnehmern bestand und zu dem meist die Familie Berve lud; hin und wieder kam man auch bei den Becks zusammen. ${ }^{16}$ Zudem sah man sich in der «Zwanglosen Gesellschaft». Die alten Netzwerke integrierten nach dem verlorenen Krieg die Besiegten aus Wissenschaft, Kultur, Politik und Verlagswesen. Im Sommer 1947 las Berve den fünften Band der «Griechischen Literaturgeschichte» Korrektur, die Wilhelm Schmid für das «Handbuch der Altertumswissenschaft» verfasst hatte; im folgenden Jahre widmete er sich dem Manuskript des zweiten Bandes der «Griechischen Religionsgeschichte» von Martin P. Nilsson. 6 oo DM erhielt der arbeitslose Althistoriker für gut 600 Seiten. ${ }^{17}$

1949 erschien Berves Aufsatzsammlung «Gestaltende Kräfte der Antike» mit Veröffentlichungen aus den dreißiger und vierziger Jahren. In der DDR stand die Leipziger Universitätsrede von 1940, die «Perikles» gegolten hatte, auf dem Index. Der Bitte Heinrich Becks, ein kurzes Vorwort voranzustellen, in dem «ganz beiläufig das Nötige» gesagt werde, verschloss sich Berve. ${ }^{18}$ Der Verlag schrieb in seiner Werbung, der Historiker habe in seinen acht Beiträgen «die zeitbedingte Bedeutung der gestaltenden Kräfte» herausgearbeitet, es werde aber «auch deutlich, wie beispielhaft das antike Geschehen war, denn es ist wie kein anderes geeignet, uns zu einer vertieften und objektiven Erkenntnis aller Geschichte, also vor allem auch der gegenwärtigen, hinzuführen». Verdrängung und Immunisierung kennzeichneten jedoch nicht nur die Politik des Verlags, sondern weite Teile der althistorischen Zunft: Berve stieg erneut zu einem der einflussreichsten Vertreter seines Faches in der Bundesrepublik auf und repräsentierte eindrücklich die personelle und wissenschaftliche Kontinuität in der Alten Geschichte in Deutschland nach 1945. ${ }^{19}$

Die erste Empfehlung, die Berve nach 1945 aussprach, galt Hermann Bengtson: Als Heinrich Beck die Nachricht erhielt, dass Bengtson am z. Juli 1946 in den Verlag komme, fuhr er mit dem Fahrrad durch das zerstörte München zu Berve, um sich beraten zu lassen, «ob Bengtson die Griechische Geschichte anvertraut werden kann». ${ }^{20}$ Die Gemeinsamkeit der pre- 
kären Existenz ließ alte Gräben überbrücken. Walter Otto hatte Bengtson einst veranlasst, publizistisch gegen Berves elitäres Konzept des «adligen Einzelmenschen» und dessen Reduktion der Alten Geschichte auf die griechisch-römische Geschichte Stellung zu nehmen. ${ }^{21}$ Doch diese wissenschaftlichen Gegensätze veranlassten Berve nicht, nach dem Zusammenbruch des «Dritten Reiches» auf Distanz zu Bengtson zu gehen: Hier empfahl vielmehr der eine Schüler Walter Ottos den anderen - und der eine amtsenthobene Hochschullehrer den anderen. Darüber hinaus hatte auch der britische Altertumswissenschaftler Arthur Darby Nock, seit 1930 Frothingham Professor of the History of Religion in Harvard, sich für das «Handbuch der Altertumswissenschaft» eingesetzt und Bengtson als Bearbeiter für die Neuauflage der «Griechischen Geschichte» empfohlen. Am 23. Oktober 1946 unterzeichnete Bengtson den Verlagsvertrag für den Handbuchband, nachdem er kurz zuvor Sund mitgeteilt hatte, dass er wieder in den Besitz seiner Kolleg-Niederschriften aus Jena gekommen sei, die 700 Seiten umfassten und ihm als Materialsammlung wichtige Dienste leisten würden. Ab dem 1. September 1946 erhielt der freigestellte Historiker bis auf Weiteres monatlich 200 Mark als Honorarvorschuss. Der Vertrag regelte später, dass, sollte bis zum Erscheinen der ersten Auflage des Bandes, für das der 31. August 1949 ins Auge gefasst wurde, «eine durchgreifende Änderung des Geldwertes eintreten», die Vorauszahlungen «nach einem den Verhältnissen angepassten Schlüssel umzurechnen» seien. ${ }^{22}$ Bis zum Erscheinen des Buches im Jahr 1951 leistete der Verlag eine Vorauszahlung von insgesamt 7200 DM. Durch diesen Vertrag hatte der Verleger Heinrich Beck dem amtsenthobenen Professor «über die schwierigste Zeit seines Lebens hinweggeholfen». ${ }^{23}$

Hermann Bengtson brachte sich systematisch für verschiedene Buchprojekte ins Gespräch. Der regelmäßige Austausch mit Sund intensivierte die Beziehung zwischen Autor und Verlag. Bengtson arbeitete zunächst an einer «Einführung in die Alte Geschichte». Er hatte erkannt, dass nach dem Ende des «Dritten Reiches» neue Lehrmittel an den Hochschulen notwendig waren. Der Verlag akquirierte das Projekt. Am 2. September 1946 teilte Sund Bengtson mit, dass der Biederstein Verlag am «letzten Freitag lizensiert» worden sei. Aufgrund der Papierknappheit bestünden verhältnismäßig geringe Produktionsmöglichkeiten, und deshalb sei das «Erstlingsprogramm» sehr begrenzt. Aber die «Einführung in die Alte Geschichte» sei für das zweite Halbjahresprogramm vorgesehen, auch wenn das nicht wesentlich reichhaltiger ausfallen könne. ${ }^{24}$ Als es trotz Sunds Versprechen bis Mitte 1948 immer noch nicht zum Abschluss des Vertrags über die «Einführung in die Alte 
Geschichte» gekommen war, wurde Bengtson ungeduldig. Er verwies darauf, dass er ein Angebot des Schwann Verlags in Düsseldorf vorliegen habe; dort werde man die Drucklegung sogleich besorgen. Die Drohung mit dem nicht eben renommierten Verlag zeigte Wirkung. Am 9. August 1948 wurde Bengtson ein Entwurf des Vertrags über die «Einführung» zugestellt. Für den Althistoriker war dies auch finanziell ein wichtiger Fortschritt, da er kurz nach der Währungsreform vom 20. Juni 1948 für dieses Werk ein Voraushonorar in Höhe von 800 DM bezog, verteilt auf acht Monate. Für seine verschiedenen Tätigkeiten für den Verlag erhielt Hermann Bengtson vom 1. Januar 194,8 bis zum 20. Juni 194,81800 RM, vom 21. Juni 194,8 bis 31. Dezember 1948 1900 DM und vom 1. Januar 1949 bis zum 31. März 1949 10oo DM. ${ }^{25}$

\section{Erfolgsautor und Berater}

Die «Einführung in die Alte Geschichte» erschien 1949 in erster Auflage. Sie war ungemein erfolgreich. Sie wurde ins Englische übersetzt, und allein von der achten und letzten Auflage von 1979 konnten fast 10 ooo Exemplare verkauft werden. Generationen von Studierenden wurde dieses Werk empfohlen, das die «Hilfs-» oder - wie Bengtson sagte - «Grundwissenschaften» vorstellte: Epigraphik, Numismatik und Papyrologie, des Weiteren Chronologie, Geographie und Anthropologie. Es bot viele bibliographische Hilfen und illustrierende Beispiele, vor allem aber kanonisierte er durch den Rekurs auf die Hilfswissenschaften das traditionelle Bild einer primär durch die historisch-kritische Methode definierten Alten Geschichte. Bengtson wollte an die Zeit vor 1933 anknüpfen, und seine Botschaft lautete: keine weltanschaulichen Experimente. Doch er selbst war tief der Volkstumsforschung der zwanziger und dreißiger Jahre verpflichtet. Völker wurden als soziale Gruppen bezeichnet, die sich bilden und wieder vergehen, und ebendiese Konzeption machte Bengtson zum vornehmsten Gegenstand der historischen Forschung. ${ }^{26}$ Der Historiker habe den Einflüssen nachzugehen, «die sich fördernd oder hemmend auf die Bildung der einzelnen völkischen Individualität ausgewirkt haben». ${ }^{27} \mathrm{Zu}$ dem spiegelte die «Einführung» biologistische Denkmuster und reproduzierte rassengeschichtliche Kategorien der dreißiger und vierziger Jahre. Die Anthropologie war - auch noch 1979 - «eine exakte Wissenschaft», die «mit Zirkel und Messband» arbeite. In Attika sei «keineswegs mit einer rein «nordischen» Bevölkerung zu rechnen», und die Spartaner hätten «das 〈nordische` Element reiner verkörpert» als beispielsweise die Ionier. ${ }^{28}$ 
Die Freiexemplare, die Bengtson von seiner «Einführung in die Alte Geschichte» 1949 über den Verlag versenden ließ, erreichten einen weiten Kreis von deutschen und ausländischen Wissenschaftlern und trugen maßgeblich dazu bei, dass der Autor und der Verlag wieder in der internationalen scientific community wahrgenommen wurden. Zu den Empfängern zählten große Namen: Michael Rostovtzeff und Charles Bradford Welles

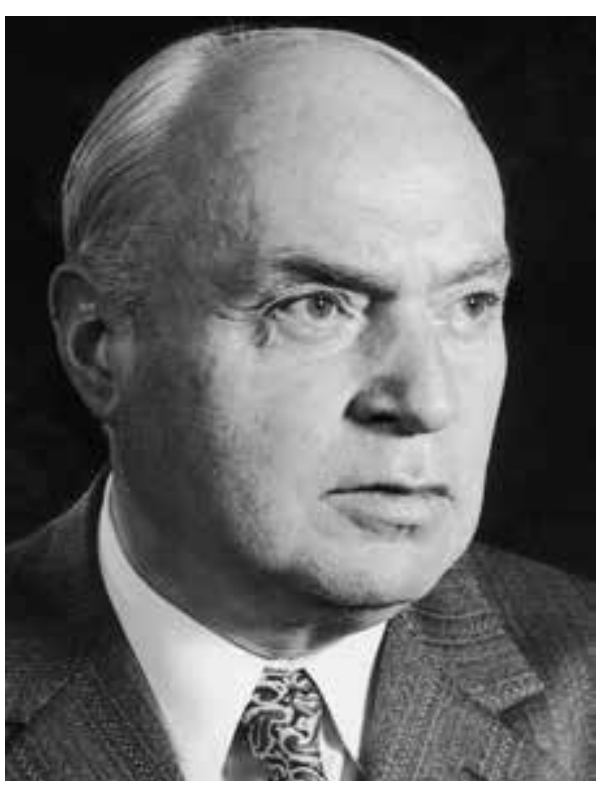

Hermann Bengtson, Herausgeber des «Handbuchs der Altertumswissenschaft» in New Haven, Martin P. Nilsson in Lund, Theodore C. Skeat in London, Harold I. Bell in Aberystwyth, William W. Tarn in Inverness, Marcus N. Tod und Felix Jacoby in Oxford, André Piganiol und Louis Robert in Paris sowie Adolf Wilhelm in Wien. Selbstverständlich wurden auch alte Verbindungen gepflegt: Die «Einführung» wurde an die Witwe seines Lehrers Otto geschickt, an Helmut Berve und an Münchner Kollegen: den Rechtshistoriker Mariano San Nicolò, die Klassischen Philologen Friedrich Klingner, Albert Rehm und Richard Harder, den Ägyptologen Alexander Scharff, den Althistoriker Fritz R. Wüst, aber auch an den Epigraphiker Günther Klaffenbach in Berlin, an den Rechtshistoriker Erwin Seidl in Erlangen, an die Althistoriker Lothar Wickert in Köln, Joseph Vogt in Tübingen, Matthias

Gelzer in Frankfurt, Franz Altheim in Halle und Johannes Straub in Erlangen sowie an den Klassischen Philologen Wilhelm Capelle in Hamburg. ${ }^{29}$ Fast identisch ist der Kreis derer, denen der Verlag zwei Jahre später Bengtsons «Griechische Geschichte» übersandte. Die Distributoren verteilten mit der Erwähnung der Bücher in Forschung und Lehre symbolisches Kapital, von dem Autor und Verlag gleichermaßen profitierten. Die Empfänger der Freiexemplare fanden sich später unter den Autoren des Handbuchs, der altertumswissenschaftlichen Reihen und Zeitschriften.

Schon Anfang Oktober 1946 hatte Bengtson ein weiteres Vorhaben ins Gespräch gebracht: Er wollte die «Weltgeschichte des Mittelmeerraumes von Philipp II. von Makedonien bis Muhammed» herausgeben, die der konservative Althistoriker Ernst Kornemann hochbetagt mitten im Zweiten Weltkrieg zu Papier gebracht hatte. Bengtson hatte das Werk noch nicht gelesen, aber oft mit Kornemann, der nach München übersiedelt 
war, darüber gesprochen. Nach Kornemanns Tod am 4. Dezember 1946 vermittelte Bengtson den Kontakt zu Kornemanns Neffen Ernst Bärend, um dem Verlagshaus die Veröffentlichung des Buches, das ursprünglich unter dem Titel «Weltgeschichte der 1000 Jahre» erscheinen sollte, zu ermöglichen. Bengtson wurde beauftragt, dem Erben mitzuteilen, dass sich der Verlag dafür einsetzen werde, das Werk rasch zu publizieren. Es musste schnell gehandelt werden, da Kornemann das Manuskript vor seinem Ableben Harrassowitz angeboten hatte. In der Tat erteilte die Militärregierung Anfang 1947 die Druckgenehmigung, und Bengtson übernahm die Herausgabe. Störend empfand der amtsenthobene Professor, dass der Neffe sich in die Verhandlungen einschaltete. Am 25. Januar 1947 schrieb er an Sund: «Bärend ist mit seinen $3^{1}$ Jahren als Student im zweiten oder dritten Semester sehr selbstbewusst. Wir werden nicht darum herumkommen, seinen Anteil an der Mitarbeit bei der Weltgeschichte im einzelnen im Vertrage genau festzulegen. Viel helfen kann er mir nicht, da er weder Latein noch Griechisch kann.» ${ }^{30}$ Bengtson und Sund ließen sich die Entscheidungshoheit jedoch nicht nehmen. Gemeinsam überlegte man, den Titel «Die Weltgeschichte der 1000 Jahre von Philipp II. von Makedonien bis Muhammed. Die Geburtsstunde des modernen Europa» zu verwenden. Sund teilte Bengtson im Juli 1947 mit, dies sei ja nun wohl nicht mehr anstößig und «jedenfalls so wirkungsvoll», dass man sich doch einmal überlegen solle, ob man nicht dabei bleiben könne. ${ }^{31}$ Damit war das Europathema in den Publikationen zur Alten Geschichte gesetzt.

Rasch stieg Bengtson mit Sunds Unterstützung neben Berve zum einflussreichen Berater in den Altertumswissenschaften auf. Die Korrespondenz belegt, dass ihm «vertrauensvoll und vertraulich» Anfragen und Manuskripte zugesandt wurden. Er unterstützte manche Projekte, andere lehnte er ab. Vieles muss bei Besuchen im Verlag besprochen worden sein. Wie Berve protegierte er die Kollegen aus der Zeit des «Dritten Reiches», die nach Flucht und Vertreibung, Entnazifizierungsverfahren und Lehrverboten allmählich wieder im akademischen Milieu Fuß fassten. Der Münchner Verlag trug so maßgeblich zur Wiedereingliederung belasteter Universitätsprofessoren in die Nachkriegsgesellschaft der Bundesrepublik bei. Allerdings konnten nicht alle Projekte realisiert werden, die Bengtson guthieß. Als im März 1947 Lothar Wickert, seit 1939 ordentlicher Professor für Alte Geschichte an der Universität zu Köln und 1941 in die NSDAP eingetreten, ${ }^{32}$ dem Verlag seine Mommsen-Biographie anbot, an der er $1933 \mathrm{im}$ Auftrag der Preußischen Akademie der Wissenschaften zu arbeiten begonnen hatte, ${ }^{33}$ empfahl Bengtson den Autor: «Ich glaube, dass er etwas 
Gutes leisten wird.» Wenig später bedauerte Bengtson allerdings, dass Wickert nun seine Mommsen-Biographie zuerst veröffentlichen wolle, denn dadurch sei zu befürchten, dass die «Römische Geschichte», die er für das Handbuch schreiben sollte, ad kalendas Graecas verschoben werde. Er fügte hinzu: «Alles, was Wickert macht, ist gut, aber sein Arbeitstempo ist viel zu langsam. Wann will er denn die Mommsen-Biographie fertig haben?» ${ }^{34}$ Wickert entschied sich, seine Biographie bei Vittorio Klostermann in Frankfurt zu verlegen. Den Handbuchband schrieb er nicht.

Bengtson legte auch für den Münchner Gräzisten Richard Harder ein gutes Wort ein, der amtsenthoben war, nachdem er im «Dritten Reich» das Institut für Indogermanische Geistesgeschichte, das Teil der von Alfred Rosenberg konzipierten, «Hohe Schule» genannten Eliteuniversität gewesen war, geleitet und für die Gestapo ein Gutachten zu den Flugblättern der Weißen Rose verfasst hatte..$^{55}$ Harder, ein ausgewiesener Spezialist für den neuplatonischen Philosophen Plotin, sollte den ersten Teil des ersten Bandes der griechischen Literaturgeschichte neu verfassen, der die Literatur «vor der attischen Hegemonie» behandelte. Bengtson bat Sund ausdrücklich, ihm diesen Gefallen zu tun, denn, so meinte er, Harder sei «doch einer unserer besten Philologen». Harder schrieb dieses Buch nicht, wohl aber erschienen 1960 seine «Kleinen Schriften» bei C.H.Beck, die sein Schüler Walter Marg herausgab. Einige Zeit musste sich Harder als Privatgelehrter und freier Schriftsteller durchschlagen, bevor er $195^{2}$ den Ruf auf ein Ordinariat für Griechische Philologie an der Universität Münster erhielt.

Gleichzeitig versuchten Sund und Bengtson, auch ausländische Autoren an den Verlag zu binden. So wollte Sund mit Unterstützung von Arthur Darby Nock dem Verlag C.H.Beck die Übersetzungsrechte an dem letzten großen Werk von Michael Rostovtzeff über die Sozial- und Wirtschaftsgeschichte des Hellenismus aus dem Jahr 1941 sichern. Doch die Verhandlungen mit dem englischen Verlagshaus waren mühsam. ${ }^{36}$ Auf englischer Seite zeigte man sich noch nicht einmal gewillt, ein Leseexemplar zur Verfügung zu stellen. Also musste sich Bengtson bemühen, die englische Ausgabe aufzutreiben. Die Verhandlungen scheiterten schließlich. Sund teilte Bengtson am 11. Juni 1947 mit: «Da ist also vorläufig nichts zu machen. Das ist insofern nicht bedauerlich, als die Veranstaltung einer deutschen Ausgabe dieses auch in England teuren Buches nach der Währungsreform wahrscheinlich eine harte Nuss sein muss. Trotzdem wollen wir bei der Stange bleiben.» C.H.Beck blieb nicht lange bei der Stange. Eine deutsche Übersetzung erschien Mitte der 1950er Jahre bei der Wissenschaftlichen Buchgesellschaft in Darmstadt. ${ }^{37}$ Auch andere Vorhaben waren nicht zu 
realisieren: Weder wurde H. Idris Bells «Egypt from Alexander the Great to the Arab Conquest» (1948) übersetzt, noch veröffentlichte der schwedische Historiker Eugène N. Tigerstedt, den Bengtson 1949 in Stockholm kennengelernt hatte, als er auf Einladung von Nilsson zu Literaturrecherchen für seine «Griechische Geschichte» in Schweden weilte, sein Buch über den Mythos Sparta im klassischen Altertum in dem Münchner Verlagshaus. ${ }^{38}$ Es war schwierig, nach Krieg und Holocaust internationale Verbindungen wiederherzustellen.

\section{Zeitschriften und Reihen}

Als Wissenschaftsverlag versuchte C.H.Beck, durch altertumswissenschaftliche Zeitschriften und Reihen Ansehen zu gewinnen, die nach dem Zweiten Weltkrieg verlegt wurden. Weiterhin erschienen die «Münchener Beiträge zur Papyrusforschung und antiken Rechtsgeschichte». Als erster Nachkriegsband wurde $195^{2}$ der dritte Teil der «Strategie in der hellenistischen Zeit» veröffentlicht. Damit hatte Bengtson sein quellen- und literaturgesättigtes Standardwerk über die Strategen abgeschlossen, die als Beamte der griechischen Poleis, als Beauftragte der Bünde, als militärische Befehlshaber und als Vertreter der hellenistischen Könige agierten. Die Arbeit orientierte sich an den traditionellen Standards der Disziplin, die schon im 19. Jahrhundert entwickelt worden waren. Bengtson hatte das umfangreiche Material zu den Strategen der hellenistischen Zeit gesammelt, gesichtet und geordnet, um, wie es im Untertitel heißt, einen «Beitrag zum antiken Staatsrecht» zu leisten, der auf «formal-juristische staatsrechtliche Konstruktionen» verzichtete.

Doch es kamen neue Reihen und Zeitschriften hinzu, die für das fachwissenschaftliche Renommee des Verlags sprachen, das vor allem Walter Otto und seiner Tätigkeit als Herausgeber des «Handbuchs der Altertumswissenschaft» zu verdanken war. Seit $195^{1}$ wurden die «Zetemata» verlegt, «Monographien zur klassischen Altertumswissenschaft», die die beiden Kieler Philologen Erich Burck und Hans Diller in Gemeinschaft mit anderen Gelehrten herausgaben. Seit 1962 erschienen unter dem Titel «Vestigia» Beiträge zur Alten Geschichte, die von der Kommission für Alte Geschichte und Epigraphik herausgegeben wurden, deren Direktor ab 1960 Helmut Berve war. Die ersten drei Bände waren im Verlag Quelle und Meyer in Heidelberg publiziert worden. Die beiden Reihen entwickelten sich rasch zu angesehenen Publikationsorganen, in denen zahlreiche Qua- 
lifikationsschriften erschienen, deren Autoren im deutschen Universitätssystem Karriere machten und durch die Veröffentlichung ihrer Dissertation oder Habilitation an den Verlag C.H.Beck gebunden wurden. Innerhalb einer Generation konnte so der Verlag zu dem führenden altertumswissenschaftlichen Verlagshaus aufsteigen; diese Entwicklung wurde noch dadurch verstärkt, dass der Zweite Weltkrieg und die anschließende Teilung Deutschlands die Verlagsbranche völlig durcheinanderwirbelte. Traditionsreiche Verlagshäuser wie B. G. Teubner in Leipzig waren durch die politischen Wirren mehrere Jahre vom Markt verschwunden. $195^{2}$ fand das Unternehmen in Stuttgart eine neue Heimat; das sächsische Stammhaus wurde in einen Betrieb mit staatlicher Beteiligung umgewandelt.

Mit Helmut Berve besprach Heinrich Beck bereits 1947 die Möglichkeit der Übernahme des «Gnomon». Längere Verhandlungen schlossen sich an; am z. Mai 1948 übersandte der Verlag dem Kieler Klassischen Philologen Walter Marg, der die Redaktion führte, den Entwurf eines Verlagsvertrags und wies darauf hin, dass in der amerikanischen Zone als Autor oder Herausgeber nur zugelassen werde, wer von der Spruchkammer höchstens als Mitläufer eingestuft worden sei. Um die Vorlage eines Fragebogens werde man nicht herumkommen. ${ }^{39}$ Der erste Band erschien im Folgejahr. Seit 1949 hatte C.H.Beck mit dem «Gnomon», der «Kritischen Zeitschrift für die gesamte Klassische Altertumswissenschaft», das von Werner Jaeger und Gerhart Rodenwaldt 1925 gegründete führende deutschsprachige Rezensionsorgan im Programm, das zuvor bei Weidmann in Berlin erschienen war. Im «Gnomon» herrschte personelle Kontinuität: Erich Burck, der während des Zweiten Weltkriegs die Würde des Dekans der Kieler Philosophischen Fakultät innehatte, war vor 1945 Redaktionsleiter und Mitherausgeber gewesen, und er saß neben dem Althistoriker Matthias Gelzer und dem Archäologen Friedrich Matz auch nach 1945 im Herausgeberkreis.

1950 kam der 43. Band der 1892 von Karl Krumbacher gegründeten «Byzantinischen Zeitschrift» bei C.H.Beck heraus; ab 1959 erschien zudem das «Byzantinische Archiv». Zuvor hatte B. G. Teubner Zeitschrift und Reihe verlegt. Herausgeber war der Münchner Byzantinist Franz Dölger, der für den Verlag im Rahmen des «Byzantinischen Handbuchs» die byzantinische Literaturgeschichte bearbeiten sollte. ${ }^{40}$ Zeitweise schien es, als könne auch die althistorische Zeitschrift «Historia», die 1950 von zwei jungen Althistorikern ins Leben gerufen wurde, dem Deutschen Karl Friedrich Stroheker und dem Schweizer Gerold Walser, ebenfalls bei C.H.Beck herauskommen. Das Organ setzte in helvetischer Tradition konsequent auf Mehrsprachig- 
keit, d. h., Beiträge wurden in englischer, deutscher, französischer und italienischer Sprache veröffentlicht, konnte auf internationale Unterstützung zählen, wurde anfangs von der französischen Besatzungsmacht gefördert und sollte den 〈Verlust> der früheren Zeitschrift «Klio» kompensieren, die bis 1944 im Leipziger Dieterich-Verlag verlegt worden war und über deren Rechte im Westen nicht verfügt werden konnte. Bengtson ventilierte bereits 1949, ob das Periodikum bei C.H.Beck erscheinen könne. Ein solches Unternehmen sei für den internationalen Ruf des Verlags von Bedeutung, ließ er Sund wissen. Doch zunächst erschien die «Historia» im Verlag für Kunst und Wissenschaft in Baden-Baden. Als Bengtson $195^{2}$ angeboten wurde, in den Redaktionsstab einzutreten, brachte er wiederum C.H.Beck ins Spiel, da die Herausgeber nach einem neuen Verlag Ausschau hielten. Doch der Franz Steiner Verlag in Wiesbaden machte das Rennen. Bengtson reagierte verärgert: Er hätte es für besser gehalten, ließ er Gerold Walser am 12. September $195^{2}$ wissen, «die Historia, zumal sie mit nicht weniger als 6 Heften im Rückstand ist, eingehen zu lassen und - etwa im Verlag Beck in München - eine neue, vorwiegend deutsche althistorische Zeitschrift herauszubringen. Die Möglichkeiten wären vorhanden gewesen.»11

Bengtson hatte sich 1948 zuversichtlich gezeigt, dass er bald wieder eine Professur erhalte. Er werde, so schrieb er damals an Sund, «wieder von einer Universität in Fesseln geschlagen werden». Das sei «so sicher, wie $2 \times 24$ ist». ${ }^{42}$ Doch zunächst erhielt er nur seine Lehrbefähigung zurück und wurde zum außerplanmäßigen Professor ernannt. Er musste weiter vom Schreiben leben. Und das gelang ihm nicht schlecht. Seine Honorarabrechnung wies $195^{1}$ ein Guthaben von 54,43,46 DM auf. Damit lag das Einkommen des Privatgelehrten und freien Schriftstellers Bengtson deutlich über dem durchschnittlichen Jahresarbeitsentgelt in Westdeutschland, das sich zu dieser Zeit auf knapp 3600 DM belief. Noch im selben Jahr erhielt er allerdings eine Anstellung als Assistent der neu gegründeten Kommission für Alte Geschichte und Epigraphik, deren erster Direktor der Münchner Ordinarius für Alte Geschichte, Alexander Graf Schenk von Stauffenberg, ein Bruder des Hitler-Attentäters, war.

Berühmt wurde Bengtson durch sein Handbuch «Griechische Geschichte von den Anfängen bis in die römische Kaiserzeit», das 1951 zuerst veröffentlicht wurde ${ }^{43}$ und 1977 seine fünfte Auflage erlebte. Der Verlag hat dieses Handbuch, das ins Neugriechische, Spanische, Italienische und Englische übersetzt wurde, auch (auf der Grundlage der dritten Auflage) 1965 als Beck'sche Sonderausgabe ohne wissenschaftlichen Apparat herausgebracht und auf diese Weise dafür Sorge getragen, dass Bengtsons Bild der 


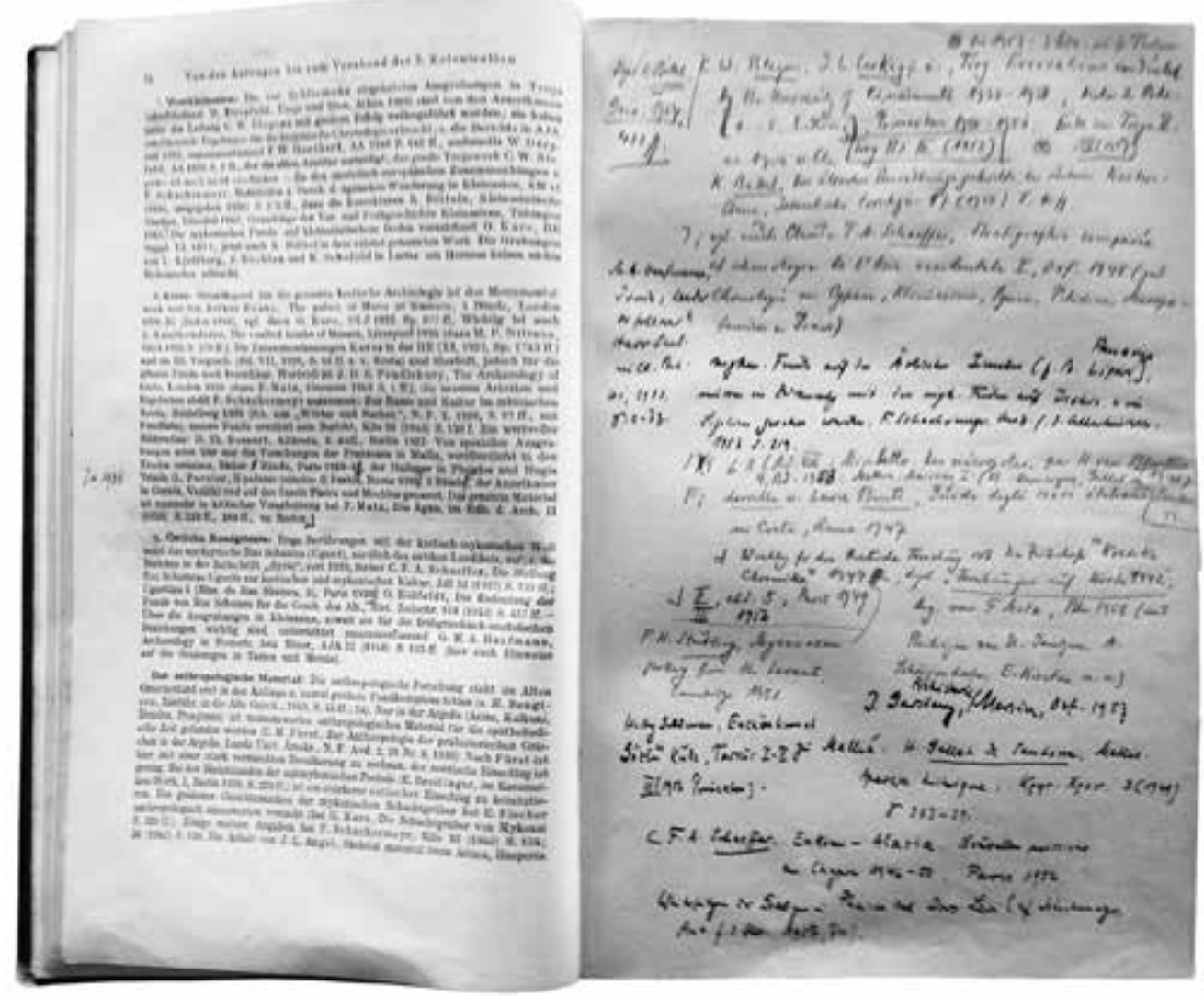

Handbuch der «Griechischen Geschichte», 1. Auflage, 1951, durchschossenes Handexemplar des Autors mit handschriftlichen Verbesserungen und Ergänzungen

griechischen Geschichte einem weiten Leserkreis vermittelt wurde. Bis Ende 2010 waren von der Sonderausgabe über 43600 Exemplare verkauft, vom Handbuchband gut 12 ooo; der Titel war damit der auflagenstärkste der Beck'schen Sonderausgaben und überflügelte sogar Spenglers «Untergang des Abendlandes», der es auf über 40000 Exemplare brachte. Die Sonderausgabe der «Griechischen Geschichte» hatte für den Verlag eine Pilotfunktion: Historische Fachbücher sollten als preiswerte, auflagenstarke Ausgaben, die ein breites Publikum erreichten, reüssieren.

Das Handbuch fasste die Ergebnisse der internationalen Forschung der letzten Dekaden zusammen und bildete den «Stand der Wissenschaft zuverlässig ab. Ein englischer Rezensent charakterisierte das Handbuch treffend: «This is perhaps a sad commentary on modern scholarship: the foundation of detailed study is so admirable and the edifice erected upon it so 
unimpressive.» ${ }^{44}$ Es sind die großen Männer, die Bengtsons Bewunderung finden, Miltiades und Leonidas, Dionysios I. von Syrakus und überhaupt die sizilischen Tyrannen, Philipp II. von Makedonien und Alexander der Große. In der Geschichte zählen Macht und Größe. Die Griechen, allen voran die Athener, werden kritisiert, den politischen Machtgedanken unterschätzt und keinen Territorialstaat geschaffen zu haben. Auf der anderen Seite schwärmt Bengtson für die Polis als dem Ursprungsort europäischer Kultur, preist Herodot und Thukydides, Platon und Aristoteles, Isokrates und Demosthenes. Dass die politische Verfasstheit der antiken Polis Grundlage der kulturellen und geistigen Leistungen der Griechen war, bedenkt er nicht, und die antike Theorie der Polis ignoriert er. Klassische Politikgeschichte steht schematisch neben Kulturgeschichte, mögliche Wechselwirkungen sind nicht Gegenstand der Erörterung.

Die Zunft war für die Kodifizierung der herrschenden Meinung und die Implementierung einer traditionellen Hermeneutik dankbar. Bengtsons Handbuch zur «Griechischen Geschichte» war ebenso wie seine «Einführung in die Alte Geschichte» ein willkommenes Hilfsmittel zur wissenschaftlichen Standortbestimmung. Zudem reintegrierte gerade das «Handbuch der Altertumswissenschaft» in die internationale Gemeinschaft der Forschenden. Schon im Mai 1946 hatten vier führende Altertumswissenschaftler in Oxford, Gilbert Murray, H. T. Wade-Gery, E. R. Dodds und Hugh Last, den Verlag nachdrücklich ermutigt, das Unternehmen fortzusetzen, und ihre Hilfe angeboten. ${ }^{45}$ Bengtsons «Griechische Geschichte» war auch deshalb willkommen, weil der Vorgängerband, den Robert von Pöhlmann verfasst hatte, noch aus der Zeit vor dem Ersten Weltkrieg stammte; und seine forschungsnahe und autoritative «Einführung», die sich auf die «Grundwissenschaften» konzentrierte, wurde nach den weltanschaulichen Kapriolen der Geschichts- und Altertumswissenschaft im «Dritten Reich» begierig aufgenommen. Der Verlag vermittelte der wissenschaftlichen Öffentlichkeit Arbeitsinstrumente, die einer nach zwölf Jahren nationalsozialistischer Herrschaft verunsicherten Disziplin Orientierung versprachen. Große Historiographie wurde nicht geboten, dafür gediegene Sammlung und Dokumentation. Der Name des Beck'schen Verlagsautors Bengtson wurde gleichsam zum Synonym für althistorische Lehrbücher. ${ }^{46}$

Doch dies ist nur die halbe Wahrheit. C.H.Beck schuf die Voraussetzungen, dass in den Altertumswissenschaften nach 1945 neue Akzente gesetzt werden konnten. Zum einen propagierte Bengtson in Abgrenzung zu einer auf die griechisch-römische Antike verengten Altertumskunde im Anschluss an seinen Lehrer Walter Otto einen universalhistorischen Ansatz, 
auch wenn er letztlich den Widerspruch zwischen dem neuhumanistischen Graecozentrismus und einer komparatistischen Universalhistorie, in der die Geschichte des griechisch-römischen Altertums aufging, nicht überwinden konnte. Zugleich griff Bengtson nach der Katastrophe des Zweiten Weltkriegs nach Europa aus. Die vom ihm präsentierte Alte Geschichte fügte sich nahtlos in die Europarhetorik der politisch konservativen Klasse der Bundesrepublik, die auf die Westintegration des neu gegründeten Staates setzte und traditionelle Stereotypen und Klischees fortschrieb. Bengtson zog fortan nur mehr mit der Feder gegen den kommunistischen Osten zu Felde. So ließ er nie einen Zweifel daran, dass die «abendländische Kultur», deren Grundlagen die «geistige Einheit der Alten Welt» bildeten, «den Lebensinhalt der heutigen Welt» bedeute und der «Gesamtablauf der Alten Geschichte» als «das Abbild einer riesigen Auseinandersetzung zwischen Abendland und Morgenland betrachtet» werden könne. ${ }^{47}$

\section{Herausgeber des Handbuchs}

Diese Faktoren erklären den Erfolg der Bücher - und den ihres Autors. $195^{2}$ wurde Bengtson auf das althistorische Ordinariat an der Universität Würzburg berufen. Ende 1953 wurde er Herausgeber des «Handbuchs der Altertumswissenschaft» und trat damit das Erbe seines Lehrers Walter Otto an. Zuvor bereits hatte er sich für diese Aufgabe durch zahlreiche Ratschläge für potentielle Autoren empfohlen, die er Georg Sund mündlich oder schriftlich zukommen ließ. Das Verhältnis zwischen Autor und Verlag war durch Reziprozität gekennzeichnet. C.H.Beck trug durch die Übergabe der Herausgeberschaft an Bengtson zu dessen Ansehen im wissenschaftlichen Feld bei, Bengtson wiederum revanchierte sich, indem er durchsetzte, dass Heinrich Beck 1954 von der Philosophischen Fakultät Würzburg «die erste große Ehrung» seines Lebens: die Ehrendoktorwürde erhielt. $^{48}$

Die Marschroute gab allerdings Heinrich Beck vor, als er am 5. Dezember 1953 den Herausgebervertrag an Bengtson sandte: «Mein Hauptwunsch hinsichtlich des Handbuchs ist nach wie vor, dass ein Bearbeiter für die Römische Literaturgeschichte gefunden wird. Dicht daneben steht fast auf der gleichen Dringlichkeitsstufe die Römische Geschichte. Dann brauchen wir einen neuen Bearbeiter für den Abschnitt der Kulturgeschichte des Alten Orients [...]. Die Bearbeitung des Alten Orients soll aber 
überhaupt aktiviert werden, und zwar handelt es sich da nicht nur um die Kultur des Zweistromlandes, sondern auch um die politische Geschichte. Vom zweiten Teil der Griechischen Literaturgeschichte ist der erste Band vergriffen; der erste Band des ersten Teils wird in Kürze auch vergriffen sein. Dies scheinen mir die ersten, wichtigsten Angriffspunkte für die Entfaltung Ihrer Tätigkeit zu sein.» ${ }^{49}$ Setzte der Verleger die Prioritäten, so hatte der Herausgeber die Pflicht, Bearbeiter zu finden und die eingereichten Manuskripte Korrektur zu lesen. Dafür erhielt er laut Vertrag ein Honorar von 25 DM pro Bogen à 16 Seiten..$^{50}$ Heinrich Beck behielt weiterhin die Initiative. Am 13. Oktober 1955 übermittelte Sund folgende Nachricht an Bengtson: «Es liegt Herrn Dr. Beck je länger, je mehr daran, dass die Kernstücke des HdA erhalten bleiben oder neu erstehen. Offenbar würde er viel lieber Geldmittel in solche Unternehmungen auch langfristig stecken, als dass er sie für den fragwürdigen Tagesruhm irgendwelcher Belletristik opfert.» ${ }^{51}$ Bengtson willfahrte und konzentrierte seine Aktivitäten darauf, Bearbeiter für die beiden Literaturgeschichten und die «Römische Geschichte» zu finden. Es hagelte Absagen. Bengtson klagte, die Klassischen Philologen trauten es sich nicht mehr zu, eine größere Arbeit zu übernehmen. Das hänge «letzten Endes mit der geistigen Situation unserer Zeit zusammen, in der Geistesblitze und rasch hingeworfene Synthesen höher geschätzt werden als die harte Arbeit am Material. Umso mehr muss versucht werden, das «Handbuch〉, auch gerade die historisch orientierten Literaturgeschichten am Leben zu erhalten. Sie sind ein sehr notwendiges Gegenmittel gegen den sich in der Philologie breitmachenden Subjektivismus.» ${ }^{52}$

Der Kreis der potentiellen Autoren wurde immer weiter gezogen. Man einigte sich auf die Reduktion des Umfangs. Jüngere Philologen wurden angesprochen. Lange Abgabezeiten konnten vereinbart werden. Alle Versuche, die beiden großen Geschichten der griechischen und römischen Literatur überarbeiten zu lassen, kamen nicht vom Fleck. Wieder reagierte der Verleger im Verbund mit seinen Mitarbeitern Richtscheid und Sund auf die neue Situation. Man dürfe sich nicht scheuen, schrieb Sund, «die griechische und die lateinische Literaturgeschichte je für sich auf mehrere Neubearbeiter oder Neuverfasser zu verteilen». ${ }^{53}$ Doch auch auf diesem Wege kam man nicht voran. Zwar wurden Verträge paraphiert, aber nicht eingehalten. Resigniert stellte Bengtson am Ende seines Lebens fest: «Immerhin habe ich fünfunddreißig Jahre lang, seit 1953, als Herausgeber gearbeitet. Mit dem Ergebnis bin ich nicht voll zufrieden, vor allem die Klassischen Philologen haben mich mehrfach im Stich gelassen.» ${ }^{54}$ 
Während Walter Otto inhaltlich neue Akzente gesetzt und das Unternehmen in den 1920er Jahren zukunftsfähig gemacht hatte, begnügte sich Bengtson als Herausgeber des Handbuchs, das Erbe zu verwalten. Es sollte ein Unternehmen der deutschen Altertumswissenschaften bleiben, ausländische Gelehrte wurden nur zögerlich angesprochen. Bengtson setzte auf seine persönlichen Kontakte, um Mitarbeiter zu gewinnen. Eine Gewichtung und eine Bewertung der Auswahl fanden nicht statt. So brachte er seine Mitherausgeber der «Historia» als Handbuchautoren ins Spiel; und für den Herausgeber des «Handbuchs der Archäologie» empfahl Bengtson zur Jahreswende 1963/64, seinen Tübinger Kollegen Ulrich Hausmann. Bengtson führte die Korrespondenz mit den Wissenschaftlern, die als Autoren gewonnen waren oder gewonnen werden sollten, und berichtete Sund, der für Heinrich Beck immer wieder Protokolle verfasste, die den schleppenden Fortgang des Unternehmens dokumentierten. Symptomatisch ist die Vergabe der Neuauflage der «Römischen Geschichte». Der Grundriss von Benedictus Niese war in der fünften, von Ernst Hohl besorgten Auflage 1922 erschienen und musste erneuert werden. Verschiedene Althistoriker wurden seit Anfang der fünfziger Jahre als potentielle Autoren diskutiert: Friedrich Vittinghoff in Köln, Hermann Strasburger in Frankfurt und Gerold Walser in Bern; Mitte 1954 äußerte der 45-jährige Bengtson zum ersten Mal die Idee, diesen Band in näherer Zukunft selbst zu schreiben, verband dieses Angebot aber mit der Erwartung, dass der Verlag in den nächsten Jahren seine «Kleinen Schriften» herausbringe. Er wollte seine Vorlesungen, die er in Würzburg hielt, als Grundlage für die Darstellung verwenden. ${ }^{55}$ Allerdings sollte die Spätantike einen eigenen Band erhalten, für den Karl Friedrich Stroheker in Tübingen, der Mitherausgeber der «Historia», ins Auge gefasst wurde. Bengtson schwankte, zögerte und ließ sich von Sund versichern, dass der Verlag «inbrünstig» wünsche, dass er sich endgültig für die «Römische Geschichte» entscheide.

Gleichzeitig war Bengtson auf die Ausdehnung seines Einflusses und seiner Zuständigkeiten bedacht. 1954, wurde er Mitherausgeber der «Münchener Beiträge zur Papyrusforschung und antiken Rechtsgeschichte», und nach dem Tod von San Nicolò am 15. Mai 1955 ging auch die rechtshistorische Abteilung des Handbuchs an Bengtson. Die hier publizierten Bände von Max Kaser über das römische Privatrecht (1955/59) und von Artur Steinwenter über das Recht der koptischen Papyri (1955) hatte San Nicolò noch vorbereitet. Kurt Lattes vielbeachtete Neubearbeitung der «Römischen Religionsgeschichte», die 1960 erscheinen sollte, hatte dreißig Jahre zuvor noch Walter Otto angeregt. Am 24. August $1957 \mathrm{kam}$ es deshalb zu 
einem Krisengipfel in Mindelheim, der vor allem den Zweck hatte, «Herrn Professor Bengtson zu zeigen, dass der Verlag für das HdA größere Aktivität entfalten möchte, als es seit der Währungsreform bisher geschehen ist». Sund vertrat die Interessen des Verlags und wollte sich auf die Argumentation des Herausgebers, die deutschen Gelehrten hätten eine «Abneigung» gegen die Abfassung von Handbüchern, nicht einlassen. Er stellte einen Aktionsplan zusammen und appellierte: «Trotzdem müssen wir suchen und bohren.» ${ }^{56}$ Ab $195^{8}$ gestand der Verlag mit dem fotomechanischen Nachdruck fehlender Bände des Handbuchs ein, dass mit deren Neubearbeitung in absehbarer Zeit nicht zu rechnen war. Zunehmend intensivierte Sund die Kommunikation mit Autoren, die Bengtson ins Gespräch gebracht hatte, die aber zögerten, einen Verlagsvertrag zu unterzeichnen. In einzelnen Fällen wurde Sund selbst aktiv. So kontaktierte er im April 1959 Wolfgang Kunkel, der für das Handbuch über die römische Verfassung schreiben sollte, und informierte den Herausgeber erst im Nachhinein. ${ }^{57}$

Bengtson suchte dem wachsenden Druck des Verlags dadurch zu begegnen, dass er regelmäßig wiederholte, er selbst werde in absehbarer Zeit eine einbändige «Römische Geschichte» liefern. Er sehe gar keine Schwierigkeit darin, die Fakten, die Quellen und die Sekundärliteratur ausreichend darzubieten. Immer mehr sähen viele Gelehrte im Handbuch nur eine Bibliographie. Das sei falsch. Dadurch sei man in die Sackgasse geraten. "Nun will er kehrtmachen und auf die richtige Straße zurückkehren.» ${ }^{58}$ Doch Bengtson bedurfte der ständigen Erinnerung. Mitte September 196o wies ihn der Verleger selbst darauf hin, dass immer noch kein Vertrag für die «Römische Geschichte» unterschrieben sei. Bengtson antwortete ausweichend, zählte andere Pflichten auf und konfrontierte den Verlag mit dem Plan, eine Universalgeschichte des Altertums zu verfassen..$^{59}$ Die von Alfred Heuß 1960 bei Westermann publizierte «Römische Geschichte» wirkte wie ein Stachel, der Bengtson anspornte, nun doch das Projekt weiterzuverfolgen. Er ließ sich von Sund ein Exemplar der Darstellung beschaffen, um dann mitzuteilen, dass dieses Werk den Handbuchband nicht überflüssig mache. Heuß' «Römische Geschichte» sei, ließ er sich wenig später vernehmen, keine eigentliche Geschichte, sondern mehr «ein Beitrag zur modernen Geistesgeschichte». Sund hatte zuvor schon weise bemerkt: «Soviel ich weiß, sind Sie und Herr Heuß in mancher Hinsicht Antipoden.» ${ }^{60}$

In der Tat waren Bengtson und Heuß Antipoden. Heuß vertrat eine völlig andere Alte Geschichte und war nicht nur als Schüler Helmut Berves, sondern schon als Verfasser einer Habilitationsschrift über «Stadt und 
Herrscher des Hellenismus» (1937) auf Bengtsons Ablehnung gestoßen. Heuß war kein Spezialist und wollte keiner sein; er hatte unter leitenden Fragestellungen über die gesamte griechisch-römische Antike gearbeitet - unter Ausschluss des Alten Orients -, er hatte in seiner MommsenBiographie von $195^{6}$ gezeigt, wie altertumswissenschaftliche Wissenschaftsgeschichte zu schreiben war, und er hatte sich allgemein mit Problemen der Geschichtsschreibung befasst. Seine 1960 zum ersten Mal erschienene «Römische Geschichte» sowie seine Darstellungen der griechischen und der römischen Geschichte in der «Propyläen»-Weltgeschichte von 1962/63 begnügten sich nicht damit, anderswo erzielte Ergebnisse zu reproduzieren, sondern stifteten historische Zusammenhänge. Antiquarische Forschung und selbstgenügsames Spezialistentum achtete er gering; stattdessen favorisierte er die generalisierende Synthese und die systematisierende Abstraktion. Er las Max Weber und Edmund Husserl und setzte sich mit Hans Freyer und Arnold Gehlen auseinander. Energisch forderte er, die Aufgabe des Historikers dürfe sich nicht im Sammeln von Quellen erschöpfen; dieser müsse vielmehr seine mit wissenschaftlicher Methode gewonnenen Erkenntnisse einer gebildeten Öffentlichkeit vermitteln. Trotz mancher Idiosynkrasie und Voreingenommenheit vermochte Heuß dem Fach als konservativer Modernisierer seit den 1950er Jahren neue Perspektiven zu eröffnen. Und er verstand sich auf große Geschichtsschreibung. ${ }^{61}$ Er konnte nicht zu C.H.Beck finden, weil dort Bengtson wissenschaftliche Arbeit auf antiquarische Exaktheit fokussierte und die genaue Dokumentation zur vorrangigen Aufgabe der Geschichtswissenschaft erklärte. Gewiss, Bengtson trug maßgeblich dazu bei, dass durch «gediegene Sachbezogenheit und Zurückhaltung in weltanschaulichem Deklarationsdrang» die deutsche Althistorie nach 1945 wieder die erwünschte internationale Geltung erlangte. Doch der Preis, der dafür zu bezahlen war, war erheblich. Denn die «neue Sachlichkeit» ${ }^{62}$ ging einher mit dem Verzicht auf eine problem- und wissenschaftsgeschichtliche Reflexion der eigenen methodischen und epistemologischen Grundannahmen. Bengtson leitete die Legitimität seines Faches aus positivistischer Produktivität ab.

Bengtsons Rekurs auf die vermeintliche Unparteilichkeit und Objektivität wertfreier Quelleninterpretation, die in der Tradition des 19. Jahrhunderts stand, war ein Merkmal der Geschichtswissenschaft in den langen fünfziger Jahren. Winfried Schulze hat zu Recht darauf hingewiesen, dass die deutschen Historiker nach 1945 an Rankes Kategorie der Objektivität anknüpften und so einen «willkommenen Fluchtraum» schufen, in dem 
die Entwicklung der jüngsten deutschen Geschichte und die Rolle der Geschichtswissenschaft «als Abweichung vom Gebot der Objektivität» interpretiert werden konnte. Auf dieser Grundlage wurde die Rückkehr zu Ranke als unverzichtbare Grundlage der historischen Wissenschaft dargestellt. ${ }^{63}$ Auch Bengtson vertraute auf eine allmähliche Annäherung an die historische Wirklichkeit, an das «Wie es eigentlich gewesen» in der Alten Welt.

Bengtson steht für die restaurativen Tendenzen des Faches, die in der Bundesrepublik durch zwei Faktoren verstärkt wurden: Einerseits kehrte kein emigrierter Althistoriker nach Deutschland zurück, andererseits sah man sich nach der Teilung Deutschlands und im Kalten Krieg in einer Frontstellung gegen den historischen Materialismus. In diesem Kontext stießen Bengtsons flammende Plädoyers für die Freiheit Europas, seine stereotype Scheidung zwischen Ost und West, zwischen Barbaren und Hellenen, und seine Ausfälle gegen den «narkotisierenden Einfluss der altorientalischen Kulturen ${ }^{64}$ nicht nur bei professionellen Altertumswissenschaftlern, sondern auch bei zahllosen Absolventen der Humanistischen Gymnasien auf breite Zustimmung. Dem wissenschaftlichen Traditionalismus entsprach ein politischer Konservativismus, den er mit seinem Verleger Heinrich Beck und dessen Mitarbeiter Georg Sund teilte.

Neue zukunftweisende Impulse gab Hermann Bengtson seit den 196oer Jahren den Altertumswissenschaften nicht mehr. Gewiss, 1962 erschien der von ihm herausgegebene zweite Band der «Staatsverträge des Altertums», die Bengtson 1958 dem Verlag C.H.Beck vermittelt hatte, nachdem in der Kommission für Alte Geschichte und Epigraphik zeitweise der Verlag Quelle und Meyer favorisiert worden war. Doch Edition und Kommentierung waren ganz traditionellen Methoden verpflichtet. Wie schon in seiner dreibändigen Monographie «Die Strategie in der hellenistischen Zeit» war Bengtson bemüht, die Quellen vollständig zu erfassen und ausführlich zu diskutieren. Sein Blick richtete sich auf Einzelheiten. Von der gelehrten Literatur ließ er sich, wie Alfred Heuß in einer Rezension zu den ersten beiden Bänden des letztgenannten Werkes 1949 treffend bemerkt hatte, die Fragen diktieren, «anstatt seine eigenen zu stellen. Fast alle seine Urteile sind Kontroversentscheidungen, Abwägen vorhandener Argumente, aber fast nie ein originaler Gedanke.» ${ }^{65}$ Heuß' gewohnt scharfes Urteil sollte sich mit Blick auf die künftige wissenschaftliche Produktion von Bengtson geradezu als prophetisch erweisen. 
Bengtson bedeutete für das Handbuchunternehmen und die Altertumswissenschaften im Verlag C.H.Beck Stillstand. Der zweite Althistoriker, der eng mit dem Verlag verbunden war, Helmut Berve, vermochte, trotz seiner intellektuellen Überlegenheit, Bengtsons Traditionalismus nicht zu neutralisieren. Mit Mühe konnten Heinrich Beck und Georg Sund den Herausgeber des Handbuchs, der die nächsten zehn Jahre «viel lieber darauf verwenden» wollte, «eine Gesamtgeschichte des Mittelmeerraumes» zu verfassen, dazu bewegen, den Band zur römischen Geschichte nun doch selbst zu schreiben. Dafür übte man moralischen Druck aus, indem man ihn vorsichtig an seine Verpflichtung dem Verlag gegenüber erinnerte, der ihm einst die Abfassung der «Griechischen Geschichte» ermöglicht hatte, machte aber auch eine Reihe konkreter Zugeständnisse: Der Druck der «Staatsverträge» wurde beschleunigt; man gestattete Bengtson, den Band «Griechen und Perser», der 1965 als fünfter Band der «Fischer Weltgeschichte» erschien, «auf der Grundlage» des Handbuchs zu schreiben; er erhielt die Zusage, dass seine Universalgeschichte im Verlag C.H.Beck verlegt werde; der Verlag wollte seine «Gesammelten Schriften» zu seinem 6o. Geburtstag herausgeben; und schließlich bekam er ein Honorar von 12 Prozent vom Ladenpreis statt der üblichen 10 Prozent. ${ }^{6}$ Pünktlich zum 20o. Verlagsjubiläum im Herbst 1963 sagte Bengtson zu, die Geschichte der römischen Republik und der Kaiserzeit für das Handbuch zu schreiben. Karl Friedrich Stroheker sollte den Teilband zur Spätantike übernehmen. Anfang Juni 1964, unterzeichnete er den Vertrag. Handschriftlich veränderte er die Zahl der Freiexemplare von 15 auf 20, denn er fand es, wie er Sund mitteilte, inakzeptabel, dass ihm gleich viele Freiexemplare wie Stroheker zuständen, obwohl er die doppelte Textmenge abliefern werde. ${ }^{67}$

1963 war Bengtson als Nachfolger Joseph Vogts nach Tübingen gegangen. Sund hatte ihm pflichtschuldig zum Ruf gratuliert. ${ }^{68}$ Zum Verlagsjubiläum am 9. September 1963 in der Aula der Ludwig-Maximilians-Universität hielt Bengtson den Festvortrag. Der Verlag unterstrich durch diese Entscheidung die Bedeutung, die die Altertumswissenschaften im Allgemeinen und Hermann Bengtson im Speziellen für den Verlag hatten. Seine Rede über «Universalgeschichte Gestern und Heute» sollte wohl als eine programmatische Äußerung zur Ausrichtung der Alten Geschichte verstanden werden; aber Bengtson verbreitete nur die bescheidene Einsicht, dass die universalhistorische Betrachtung des Altertums «neue Gesichtspunkte, neues Leben und ein weites neues Betätigungsfeld für die histori- 


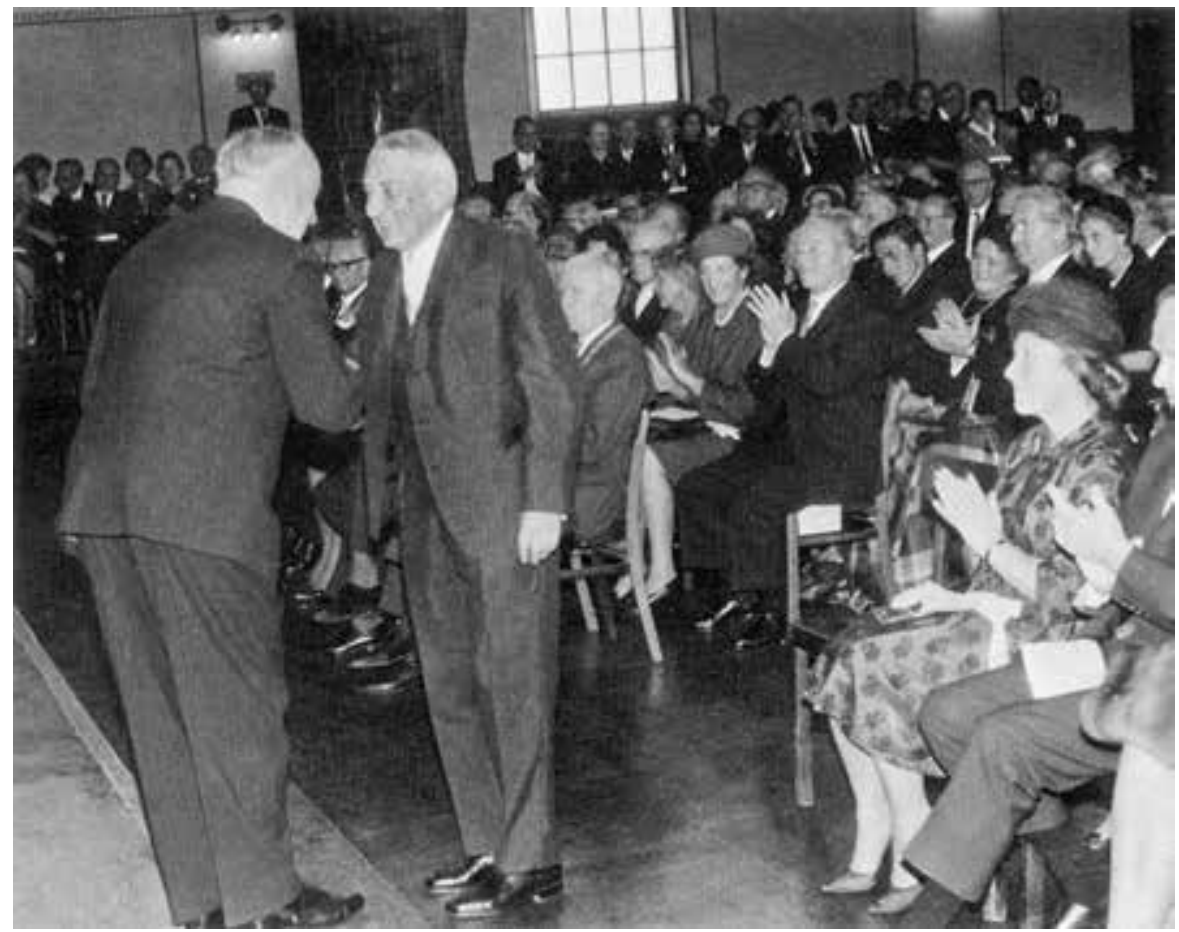

Der Verleger Heinrich Beck (rechts) dankt dem Festredner Hermann Bengtson beim 200. Verlagsjubiläum 1963

sche Wissenschaft» bringe, und forderte am Ende, sich mit möglichst vielen Sprachen und Kulturen der Alten Welt zu beschäftigen. ${ }^{69}$ Die Ansprache war jedoch fraglos besser als das Gedicht, das er kurz danach an Sund schickte, um ihn an das Honorar zu erinnern: «Anstatt noch länger abzuwarten, / verschickt der Redner seine Karten. / Er weiß, es kann ja nichts passieren, / Denn der Verlag wird honorieren.» Heinrich Beck antwortete zwei Tage später, dankte für die «interessante» Rede und stellte ein Honorar in Aussicht, das sich auf $75^{\circ}$ DM belief. ${ }^{70}$

Das Manuskript für die «Römische Geschichte» erreichte den Verlag fast ein Jahr vor dem verabredeten Termin Anfang Januar 1966. Zum 1. März desselben Jahres war Bengtson an die Ludwig-Maximilians-Universität gewechselt. Den Ruf nach München hatte er ersehnt, denn es handelte sich für ihn weniger um die Nachfolge seines Vorgängers Alexander Graf von Stauffenberg als vielmehr um das Ordinariat seines Lehrers Walter Otto. ${ }^{71}$ Der homo academicus Bengtson, altertumswissenschaftlicher Autor, Herausgeber und Berater des Verlags C.H.Beck, hatte, so schien es, den Höhepunkt seiner Laufbahn erreicht, der professorale Aufsteiger aus einfachen 
Verhältnissen die höchste Anerkennung in seinem Feld gefunden. Doch Hermann Bengtson war nur zweite Wahl, und die Philosophische Fakultät der Universität München setzte ihn denn auch 1964, bei der Besetzung des vakanten Ordinariats folgerichtig secundo loco. An erster Stelle stand Alfred Heuß, der damals an der Universität Göttingen lehrte und den Ruf nach München ablehnte.

Die enge Verbindung des Verlags C.H.Beck zu Hermann Bengtson war, je länger sie währte, der Entwicklung der Zunft, aber auch der Entwicklung des altertumswissenschaftlichen Programms innerhalb des Hauses abträglich. Bengtson verfocht den Primat der politischen Geschichte. «Volk» und «Nation», «Staat» und «Reich» wurden als erkenntnisleitende Begriffe festgeschrieben. Das «schöpferische Ingenium» stand im Vordergrund, die «Herrschergestalten», die großen Männer, die Geschichte machten. Bengtson teilte organizistische Vorstellungen über den Aufstieg und Niedergang von Völkern und Kulturen, die wuchsen, blühten, alterten und vergingen. An Systemanalysen hingegen hatte er keine Freude. Die Sozialwissenschaften lehnte er ab. Einen eindrücklichen Beweis hierfür bot die «Römische Geschichte», deren Erscheinen 1967 Heinrich Beck begrüßte: «Mit dem neu erschienenen HdA-Band beginnt sich dank Ihrer Tatkraft, Ihres Fleißes und kluger Beschränkung eines vielfältigen Stoffes wie seinerzeit bei Ihrer «Griechischen Geschichte` eine Lücke zu schließen, die durch viele Jahre hindurch sehr empfunden wurde.» ${ }^{72}$ Das Handbuch, in dessen Vorwort Bengtson betonte, er habe es verfassen müssen, da er keinen Bearbeiter habe finden können, ${ }^{73}$ war von der zweibändigen «Römischen Geschichte» von Ernst Kornemann beeinflusst, deren Neuauflage Bengtson bereits im Frühjahr 1949 - allerdings vergeblich - im Biederstein Verlag hatte herausgeben wollen. Damals hatte er hervorgehoben, als Hochschullehrer Kornemanns Werk immer wieder empfohlen zu haben. ${ }^{74}$ Bengtson verband mit Kornemann die Liebe zu den römischen Bauern, und beide betonten den Primat der Außenpolitik und den Antagonismus zwischen «Führer» und «Masse». ${ }^{75}$ Das Handbuch hat, wie von der Kritik längst gesehen, erhebliche Schwächen, es fehlt an souveräner Beherrschung des Stoffes und an eingehender Kenntnis der Forschung. Die Darstellung des Zweiten Makedonischen Krieges ist etwa so umfangreich wie die Ausführungen über die römische Gesellschaft zur Mitte des 2. nachchristlichen Jahrhunderts. ${ }^{76}$ Über die augusteische Neuordnung heißt es: «Das Prinzipat ist nicht an einem Tag erbaut worden.» ${ }^{77}$ In den einleitenden Ausführungen über «Die neueren Forschungen» wird Michael Rostovtzeffs grundlegende «Social and Economic History of the Roman 
Empire» in der Ausgabe von 1926 und nicht in der maßgeblichen von 1957 zitiert, und Ronald Symes epochales Werk «The Roman Revolution» (1939) taucht erst gar nicht auf. ${ }^{78}$ In verfassungsrechtlichen Zusammenhängen ist häufig nicht Mommsens «Staatsrecht», sondern Ernst Meyers Kompendium «Römischer Staat und Staatsgedanke» zitiert. ${ }^{79}$ Kurzum: Moses I. Finley war nach der Lektüre so bestürzt, dass er am Fortschritt in der Historiographie der Alten Welt zweifelte. ${ }^{80}$ Das Buch erschien 1982 in dritter Auflage und wurde - wie die «Griechische Geschichte» - auch in einer Sonderausgabe ohne Anmerkungsapparat vertrieben, die sich bestens verkaufte. Bis Ende 2010 gingen über 37000 Exemplare über den Ladentisch.

Hatte Bengtson in den fünfziger Jahren erheblichen Einfluss auf die Entwicklung des Faches ausgeübt, so hatte er Mitte der sechziger Jahre seinen Zenit überschritten. Die Geschichtswissenschaft, und selbst die eher behäbige Althistorie, öffnete sich damals neuen Fragestellungen und Methoden. Vor allem die Sozialgeschichte fand Eingang in die Forschungen; Friedrich Vittinghoff, der von der Volkstumsforschung kam, machte diese Sparte in der Alten Geschichte hoffähig. ${ }^{81}$ Zudem wurden neuere Ansätze vor allem der angelsächsischen und französischen Forschung rezipiert, und ein kleiner, aber feiner Kreis von Althistorikern wandte sich theoretischen und methodologischen Problemen zu. 1965 schrieb Alfred Heuß über die Bedeutung Max Webers für die Alte Geschichte, ${ }^{82}$ drei Jahre später reflektierte er über eine Theorie der Weltgeschichte und untersuchte «Max Weber» und das Problem der Universalgeschichte. ${ }^{83} 1966$ hielt Christian Meier seinen inzwischen berühmt gewordenen Vortrag über Sinn und Ziel der Alten Geschichte. ${ }^{84}$

Diese Entwicklungen gingen an Bengtson vorbei. Den Paradigmenwechsel der sechziger Jahre ignorierte er. Er bewegte sich in einer Welt der politischen und wissenschaftlichen Enge. Innovative Impulse gingen von seinen Arbeiten nicht aus. Aber der Verlag C.H.Beck stützte Bengtsons einflussreiche Position innerhalb des wissenschaftlichen Feldes auch dann noch, als abzusehen war, dass er auch als Herausgeber die Veränderungen der Zeit nicht wahrnahm, sondern sich an Überkommenes klammerte. Er versuchte auch mit Hilfe seines Hausverlags, weiterhin Einfluss auf die Entwicklung des Faches Alte Geschichte auszuüben: als Autor, als akademischer Lehrer, als Gutachter. C.H.Beck hatte als einer der führenden altertumswissenschaftlichen Verlage durch seine Personal- und Programmpolitik das bisweilen starre Beharren auf überkommenen Modellen in der deutschsprachigen Altertumswissenschaft befördert und die Auseinandersetzung mit neuen Fragestellungen und Methoden, die in 
den Altertumswissenschaften außerhalb Deutschlands diskutiert wurden, verzögert.

Veränderungen wollte der neue Lektor Ernst-Peter Wieckenberg durchsetzen, der seit Juni 1967 mit Bengtson über das althistorische Programm im Allgemeinen und das Handbuch im Besonderen korrespondierte. Wieckenberg forderte energischer als Sund neue Initiativen, um das Unternehmen flottzumachen, suchte Kontakte zu potentiellen Autoren, erkundigte sich nach dem Stand der Arbeiten und schlug neue Themengebiete vor. ${ }^{85}$ So brachte er einen Grundlagenband zu den «Methoden der Klassischen Philologie» ins Gespräch, den Manfred Fuhrmann hätte übernehmen sollen, oder eine Darstellung zur Wissenschaftsgeschichte der Alten Geschichte, für die sich Karl Christ anerbot. Beide Projekte torpedierte Bengtson. Die Kommunikation mit dem statusbewussten Ordinarius war schwierig, und es kam zu Missstimmungen. Bengtson wollte sich von «Dr. Wieckenberg» nicht sagen lassen, wie er seinen Herausgeberpflichten nachzukommen habe. Doch der Cheflektor ließ nicht locker. Im Mai 1974, als bereits Wolfgang Beck die Geschäfte führte, wurde Stroheker, der den Band zur Geschichte der Spätantike übernommen hatte, aber nichts lieferte, ein Ultimatum gesetzt und als Ersatzkandidat André Chastagnol in Paris sowie das Ehepaar Averil und Alan Cameron vorgeschlagen. Wieckenberg setzte mithin auf eine Internationalisierung des Unternehmens. Wenig später plädierte er mit Nachdruck für dessen inhaltliche und methodische Öffnung. Im Handbuch sollte ein Band zur Sozialgeschichte des Altertums erscheinen: «Es ist ganz selbstverständlich, dass eine sozialgeschichtliche Darstellung exakt aus den Quellen gearbeitet werden muss, aber ich glaube, wir würden darüber hinaus wünschen, dass der Verfasser einer jüngeren Forschergeneration angehört und politisch - ich verstehe das im weitesten Sinn des Wortes - eher zu den fortschrittlichen Köpfen zu rechnen ist.» Wieckenberg konnte im Juli 1974, Bengtson das Zugeständnis abringen, dass der progressive englische Althistoriker Moses I. Finley, Professor für Alte Geschichte an der Universität Cambridge, gefragt werden sollte, ob er diesen Band verfassen wolle. Später gab Bengtson nach einer Intervention Wieckenbergs auch seinen anfänglichen Widerstand gegen einen englischsprachigen Band in der Reihe auf. ${ }^{86}$

Wieckenberg handelte sofort. Am 18. Juli wollte er von Finley wissen, ob er bereit sei, eine Sozialgeschichte der Antike oder eine Sozialgeschichte Griechenlands für das Handbuch zu schreiben. Der Band könne durchaus auf Englisch erscheinen. Zugleich wollte er die deutschen Rechte an Finleys Buch «The Ancient Greeks» erwerben. Mit dem Übersetzungs- 
projekt war Finley sehr einverstanden, ${ }^{87}$ aber zu einer definitiven Zusage, eine Sozialgeschichte zu schreiben, konnte er sich nicht durchringen. Er sei im Prinzip interessiert, wolle aber nicht, dass der Verlag zwei Jahre auf eine Antwort warten müsse. Wieckenberg stellte daraufhin in Aussicht, dass er sich im Sommer 1976 wegen der Sozialgeschichte wieder an Finley wenden werde. «Uns läge sehr daran, dass Sie zumindest die Sozialgeschichte Griechenlands für uns schrieben. Das internationale Ansehen, das Sie genießen, würde uns - ich sage das ganz offen - bei unseren Bemühungen helfen, dem Handbuch neue Autoren vor allem auch im Ausland zu gewinnen. Aber natürlich wären wir auch auf das Werk selber sehr gespannt.» ${ }^{88}$

In den ersten Jahren verschaffte Ernst-Peter Wieckenberg sich eine Übersicht. 1976 legte er «Bemerkungen zum Handbuch der klassischen Altertumswissenschaft» vor, mit denen er auf das Unternehmen zurückblickte, einen Überblick über abgeschlossene, aber noch nicht erfüllte Verträge bot, die einzelnen Abteilungen einer kritischen Überprüfung unterwarf und Gedanken zur Neukonzeption äußerte. Seit 1965 erschien pro Jahr ein Titel, mehrere Bände waren zum Teil grundlegend überarbeitet worden. Dem standen zahlreiche nicht erfüllte Verträge gegenüber; in Einzelfällen gab es nur Vorverträge, oder der Abgabetermin des Manuskripts war offengelassen. Wieckenberg stellte die Frage nach der Abgrenzung zum «Handbuch der Vorgeschichte», das Hermann Müller-Karpe seit 1966 im Verlag herausgab, argumentierte für eine noch stärkere Berücksichtigung der Kulturen außerhalb der griechisch-römischen Welt, plädierte für einen Band über die Kelten und die Etrusker, wollte die Sozial- und Wirtschaftsgeschichte, aber auch die Agrar- und Bevölkerungsgeschichte behandelt sehen und regte vorsichtig an, für einzelne Abteilungen, die Bengtson «etwas ferner» lägen, drei bis vier Mitherausgeber zu bestimmen, da «unter den jüngeren Altertumswissenschaftlern» kaum «noch einmal ein Mann zu finden» sein dürfte, «der in der Lage wäre, die Rechte und Pflichten dieser Alleinherausgeberschaft in ihrem vollen Umfang wahrzunehmen. Die Zukunft des Handbuchs kann nur so aussehen, dass wir mehrere Herausgeber zu einem Herausgebergremium vereinigen.» Wieckenberg forderte zudem, dass ein Gesamtplan entworfen werde, «der mehr ist als nur eine Liste von Desiderata». Der Plan müsse auf die Frage nach der Abgrenzung des «Handbuchs der Altertumswissenschaft» zum «Handbuch der Archäologie» und zum «Handbuch der Vorgeschichte» antworten; dies sei kein technisches, sondern ein epistemologisches Problem. Geklärt werden müssten die Funktion des Handbuchs «im Rahmen der heutigen 
Altertumswissenschaft» und seine Aufgaben «für eine historische Information suchende Öffentlichkeit». ${ }^{89}$

Bengtson war nicht imstande, auf diese grundsätzlichen Fragen zu antworten. Anfang der achtziger Jahre erneuerte Wieckenberg seine Forderung nach einer reflektierten Standortbestimmung des Handbuchs, wollte ein Herausgeberteam, rief die Notwendigkeit der internationalen Ausrichtung in Erinnerung und sprach sich nun auch für einen Wechsel in der Leitung aus. Wolfgang Beck machte sich diese Vorschläge zu eigen und unterbreitete sie vorsichtig Bengtson. Ziel sei es zu gewährleisten, dass das Handbuch «Weltniveau erreichen» könne..$^{90}$ Internationalisierung, thematische Öffnung und editorische Arbeitsteilung waren die Antworten der Verlagsleitung auf die Stagnation des Unternehmens. Mit Bengtson waren diese Reformen nicht umzusetzen. Er zeigte sich zufrieden, wenn ein Band veröffentlicht wurde oder ein neuer, vielversprechender Autor gewonnen werden konnte, wie etwa Alexander Demandt, der im Frühjahr 1975 den Vertrag für den Teilband zur Spätantike unterzeichnete. ${ }^{91}$ Der seit 1977 emeritierte Lehrstuhlinhaber hatte andere Sorgen: Er wollte einen seiner Schüler zu seinem Nachfolger als Herausgeber bestimmen, was im Verlag jedoch auf Widerstand stieß. Man reflektierte andere Lösungen und wollte Christian Meier um Rat fragen. ${ }^{92}$

Doch man scheute davor zurück, sich von Bengtson zu trennen, da er in kurzer Folge «Sachbücher» zu altertumswissenschaftlichen Themen publizierte, die in der Zunft auf Ablehnung stießen, aber vom Publikum gekauft wurden. Man umwarb Bengtson als auflagenstarken Erzähler, der es darauf anzulegen schien, die Sachbücher zur Alten Welt alleine zu schreiben. Er vernachlässigte zuerst und behinderte später die Entwicklung eines kohärenten altertumswissenschaftlichen Programms, begnügte sich mit der rhetorischen Beschwörung der hehren Handbuchtradition und ließ sich von Lektor und Verleger hofieren. C.H.Beck veröffentlichte 1974, zu Bengtsons 65. Geburtstag seine «Kleinen Schriften», die sich als Ladenhüter entpuppten - ein Manko freilich, das diesem gesamten literarischen Genus anhaftet. ${ }^{93}$ Man zeigte sich in der Wilhelmstraße beunruhigt, wenn Bengtson ein Buch in einem anderen Verlag herausbrachte, ertrug seine Eigenheiten, kam ihm bei Honorarforderungen entgegen und entschuldigte sich wortreich, wenn er darüber Klage führte, dass der Verlag die Werbung für seine Bücher vernachlässige und in einem Katalog seinen Namen als Herausgeber vergessen habe. ${ }^{94} 1975$ erschienen die «Herrschergestalten des Hellenismus», zwei Jahre später «Marcus Antonius» und 1979 «Die Flavier». Die Bücher mussten intensiv lektoriert werden, da 
sie stilistische Härten und unverständliche Formulierungen enthielten. ${ }^{95}$ Entscheidender waren indes andere Defizite, die der Verlag mit Blick auf den Sachbuchmarkt ignorierte: Die Bücher stellten keine Fragen, ignorierten die neuere Forschung und repetierten obsolete Weisheiten. Der Kölner Althistoriker Werner Eck rezensierte «Die Flavier» in dem von C.H.Beck verlegten Organ «Gnomon» und reihte auf vier Seiten in Petitsatz addenda et corrigenda zu zwei (von fünfzehn) Kapiteln auf. Sein Fazit lautete: Der Versuch, die Herrschaft der flavischen Kaiser darzustellen, sei «schon an den elementarsten Voraussetzungen historischen Arbeitens gescheitert». ${ }^{96}$

C.H.Beck verlegte 1981 noch «Kaiser Augustus» und 1987 «Die Diadochen». Danach war Schluss: «Die hellenistische Weltkultur», die Bengtson dem Verlag angeboten hatte, erschien 1988 bei Franz Steiner in Stuttgart, und «Gestalter der Alten Welt» bei Wewel in München. 1984 hatte man zudem das Manuskript zu dem Buch «Philipp und Alexander der Große. Die Begründer der hellenistischen Welt» nach einer internen Prüfung mit groBem diplomatischen Aufwand zurückgesandt; Bengtson brachte es daraufhin bei Callwey heraus. ${ }^{97}$ Die Auflagenzahlen zeigten, dass sich von den bei C.H.Beck verlegten Büchern der jüngeren Vergangenheit nur die Augustusbiographie verkaufte. ${ }^{98}$ Bengtsons schriftliche Anfrage aus dem Jahr 1988, ob seine 120-seitige Autobiographie bei C.H.Beck veröffentlicht werden könne, wurde abgewiesen. ${ }^{99}$ Die Zusammenarbeit, die 1936 begonnen hatte, war endgültig beendet. Am 2. November 1989 starb Bengtson 8o-jährig.

Bengtson war ein Repräsentant der Restauration. Weder als Autor noch als Herausgeber konnte er an die Tradition seiner Vorgänger Robert von Pöhlmann und Walter Otto anknüpfen, die ihrem Fach nachhaltig neue Perspektiven eröffnet hatten. Selbst bei der Organisation der Herausgeberschaft kamen die Impulse über Jahrzehnte nicht von Bengtson, sondern aus dem Verlag. Hier hielt man Bengtson lange, zu lange die Stange, weil er für die expansive Strategie auf dem Sachbuchmarkt willkommen war. Dabei erkannte man früh, spätestens unter dem Cheflektorat Wieckenbergs, seine wissenschaftlichen und organisatorischen Defizite. Der Band für die lateinische Epigraphik etwa wurde gleich zweimal vergeben: zunächst an Ekkehard Weber in Wien, dann an Géza Alföldy in Heidelberg. ${ }^{100}$ Aber Wieckenberg schwächte nicht, wie behauptet wurde, ${ }^{101}$ die Alte Geschichte zugunsten der Neuesten Geschichte, vielmehr schwächte der Verlag durch sein langes Festhalten an Hermann Bengtson die Altertumswissenschaften insgesamt. Überalterte Strukturen wurden im Haus nicht in Frage gestellt und weitreichende Entscheidungen eher von persönlichen 
Loyalitäten als von objektivierbaren Kriterien abhängig gemacht. Innovationen waren so nicht durchzusetzen. Letztlich unterliefen Bengtsons späte Monographien die ambitionierte Strategie, der sich Wieckenberg verschrieben hatte und die darauf ausgerichtet war, den Verlag zu einem erfolgreichen und angesehenen wissenschaftlichen Publikumsverlag zu machen, der auch auf dem Gebiet der Sachbücher Solides produzierte. Wieckenberg musste notwendigerweise auf eine andere Epoche ausweichen, um C.H.Beck als führenden geschichtswissenschaftlichen Verlag zu positionieren. Er tat es mit großem Erfolg. Doch auch die Altertumswissenschaften gab er nicht auf, sondern schuf die Grundlagen dafür, dass sie sich in der Ära nach Bengtson wieder erholen konnten. 